\title{
Severe acquired subglottic stenosis in neonatal intensive care graduates: a case-control study
}

\author{
Rebecca E Thomas, ${ }^{1,2}$ Shripada C Rao, ${ }^{1,2}$ Corrado Minutillo, ${ }^{1}$ Shyan Vijayasekaran, ${ }^{3}$ \\ Elizabeth A Nathan ${ }^{4}$
}

\begin{abstract}
${ }^{1}$ Neonatal Clinical Care Unit, Princess Margaret Hospital for Children and King Edward Memorial Hospital for Women, Perth, Western Australia, Australia

${ }^{2}$ School of Paediatrics and Child Health, Centre for Neonatal Research and Education, University of Western Australia, Perth, Western Australia, Australia

${ }^{3}$ Department of Otolaryngology, Princess Margaret Hospital for Children, Perth, Western Australia, Australia

${ }^{4}$ Biostatistics and Research Design Unit, School of Women's and Infants' Health, University of Western Australia, Perth, Western Australia, Australia
\end{abstract}

\section{Correspondence to} Dr Rebecca E Thomas, Division of Neonatology, The Hospital for Sick Children, Toronto, Ontario M5G 1X8, Canada; becthomas73@gmail.com

Received 2 March 2017 Revised 1 August 2017 Accepted 4 August 2017 Published Online First 2 September 2017
Check for updates

To cite: Thomas RE, Rao SC, Minutillo C, et al. Arch Dis Child Fetal Neonatal Ed 2018;103:F349-F354.

\section{ABSTRACT}

Objective To analyse current incidence and risk factors associated with severe acquired subglottic stenosis (SASGS) requiring surgical intervention in neonates.

Design Retrospective case-control study.

Setting Sole tertiary children's hospital.

Participants Patients who underwent surgical intervention for SASGS from January 2006 to December 2014. For each neonatal intensive care unit (NICU) graduate with acquired SASGS, two controls were selected (matched for gestation and year of birth). Main outcomes and measures Incidences were calculated and cases and controls compared using conditional logistic regression analysis to identify risk factors for SASGS.

Results Thirty-seven NICU graduates required surgical intervention for SASGS of whom 35 were $<30$-week gestation at birth. The incidence of SASGS in surviving children who had required ventilation in the neonatal period was $27 / 2913(0.93 \%)$. Incidence was higher in infants $<28$-week gestation $(24 / 623=3.8 \%)$ compared with infants $\geq 28$-week gestation $(3 / 2290=0.13 \%$; $p=0.0001)$. On univariate analysis, risk factors for SASGS were: higher number of intubations ( 4 vs $2 ; p<0.001$ ); longer duration ventilation ( 16 vs 9.5 days; $p<0.001$ ); unplanned extubation ( $45.7 \%$ vs $20.0 \%$; $p=0.007$ ); traumatic intubation (34.3\% vs $7.1 \% ; p=0.003)$ and oversized endotracheal tubes (ETTs) (74.3\% vs $42.9 \%$; $\mathrm{p}=0.001$ ). On multivariate analysis, risk factors for SASGS were: Sherman ratio $>0.1$ (adjusted $O R(a O R)$ $6.40 ; 95 \% \mathrm{Cl} 1.65$ to 24.77$) ;$ more than five previous intubations (aOR 3.74; $95 \% \mathrm{Cl} 1.15$ to 12.19); traumatic intubation (aOR 3.37; 95\% Cl 1.01 to 11.26).

Conclusions SASGS is a serious consequence of intubation for mechanical ventilation in NICU graduates, especially in preterm infants. Minimising trauma during intubations, avoiding recurrent extubation/reintubations and using appropriate sized ETTs may help prevent this serious complication.

\section{INTRODUCTION}

Severe acquired subglottic stenosis (SASGS) in neonatal intensive care unit (NICU) graduates is a serious consequence of endotracheal intubation for mechanical ventilation, which incurs a high cost to the individual patient and family and to the healthcare system.

The reported incidence of subglottic stenosis (SGS) in this group ranges from $0 \%$ to $11 \%,{ }^{1-16}$ but is generally believed to be between $0 \%$ and $2 \% .^{12}$ The main reported risk factors for SASGS are low birth weight, low gestational age, longer duration of

\section{What is already known on this topic?}

- Incidences and risk factors for development of subglottic stenosis have previously been reported, but most reports are from 1970s and 1980s when care of neonates was different and surviving infants were of higher gestation and birth weight.

- Previous studies varied in definition of subglottic stenosis, population studied and suffered from low numbers, challenging meaningful analysis.

\section{What this study adds?}

Up-to-date incidence of severe acquired subglottic stenosis from a large cohort of ventilated neonates, enabling benchmarking.

- A breakdown of incidences for each gestational age and differing weight categories.

- Identification of risk factors for severe acquired subglottic stenosis to enable neonatal intensive care units to implement preventative strategies.

intubation, traumatic intubation, multiple numbers of endotracheal tubes (ETTs), a large diameter ETT and infant activity level. ${ }^{5-7} 91416-20$ These reports have varied in their definition of SASGS, the method used for diagnosis and the population studied. In addition, due to the rarity of SASGS, many studies have suffered from low numbers making it difficult to perform any meaningful analyses. The majority of reports are from the 1970s and 1980s when the care of neonates in the intensive care was quite different and the surviving neonates were of higher gestational age and birth weight. Recent advances in neonatal intensive care have resulted in increased survival of extremely low birthweight infants. There have been no published studies on incidence of acquired SGS in neonates since $2007^{21}$ or on the associated risk factors since $2000 .^{16}$

Therefore, we aimed to analyse the current incidence and risk factors associated with SASGS requiring surgical intervention in NICU graduates.

\section{METHODS}

We performed a retrospective case-control study of NICU graduates who developed SASGS requiring surgical intervention over a 9-year period from January 2006 to December 2014. Princess Margaret 
Hospital for Children (PMH), Perth is the only tertiary children's hospital in the state of Western Australia (WA) and caters to a total population of nearly 2.5 million people. King Edward Memorial Hospital for Women (KEMH) is the sole tertiary perinatal centre in the entire state of WA. The combined neonatal directorate of KEMH and PMH care for $>3000$ neonates per year, of whom, approximately 500 receive mechanical ventilation. All newborn infants in the state requiring level 3 neonatal care are managed in one of these institutions. Being the sole tertiary paediatric centre in the state, $\mathrm{PMH}$ is the only place where advanced surgical airway procedures are performed children.

\section{Inclusion criteria}

Cases of SASGS were defined as children with SGS who required laryngotracheal reconstruction (LTR), cricoid split or tracheostomy and had previously been intubated in the neonatal period. They were initially identified from the ENT database and confirmed as having received intubation in the neonatal period by checking the NICU database. The NICU database is a centralised database that has information about all neonates admitted across both sites (KEMH and PMH). The symptoms of SASGS could have appeared while still in the NICU or following discharge home.

\section{Exclusion criteria}

Children who had surgical intervention for SASGS, but were not previously intubated in the neonatal period, those with genetic syndromes, congenital SGS and those who had their neonatal care outside of our institution were excluded. Congenital SGS was defined as SGS diagnosed on laryngoscopy where the patient had never previously been intubated or where there was other associated airway anomalies.

For each case, two matched controls were selected randomly from the centralised NICU database. The controls were matched for gestation and year of birth. The clinical details of the study participants were obtained by reviewing their medical records. Information was collected on gestational age, birth weight, age at presentation, laryngoscopy findings prior to surgery graded according to Myer-Cotton grading system ${ }^{22}$ where available, details of surgical airway procedures and age at surgical intervention. The details of number of intubations, days intubated, unplanned extubations (an extubation which had not been medically ordered, i.e., accidental), size of ETT, number of intubation attempts, traumatic intubations (where fresh blood was reported immediately postintubation or there was a written comment of 'traumatic intubation' in patient records), culture-proven sepsis (blood culture positive) and cytomegalovirus (CMV) infection. The Sherman Ratio ${ }^{7}$ (ETT internal diameter $(\mathrm{mm})$ /gestational age) was calculated for each intubation episode to assess appropriateness of ETT size. A Sherman ratio of $>0.10$ indicates that the ETT is disproportionately larger for the gestational age of the infant. Similar information was collected for the controls.

Normal intubation practice during the study period was to use uncuffed Portex siliconised ETTs. In general, infants $<1000 \mathrm{~g}$ received $2.5 \mathrm{~mm} ; 1000-2000 \mathrm{~g}$ received $3.0 \mathrm{~mm} ; 2000-3000 \mathrm{~g}$ received $3.0-3.5 \mathrm{~mm}$ and $>3000 \mathrm{~g}$ received $3.5 \mathrm{~mm}$ ETT. The predominant route of intubation was orotracheal.

Incidences of SASGS were calculated for infants born from 2006 to 2012 inclusive, as some of the neonates born from 2013 onwards may not have yet presented with SASGS. The denominator for population incidence was from the data of registered births from WA Government over that time period. The denominators for NICU admissions and ventilated patients were obtained from the NICU databases.

Statistical analyses were performed using IBM SPSS V.20.0 for Windows (Armonk, NY: IBM Corp) and StatXact V.8.0, Cytel Inc, 2007. Continuous data were summarised using medians, IQR and ranges (R), and categorical data summarised using frequency distributions. Univariate comparisons of continuous outcomes were conducted using general linear models with matched cases and controls modelled as random effects. Conditional logistic regression was used to test the association between categorical intubation characteristics and SASGS univariately, and multivariately with simultaneous modelling of other candidate risk factors, including assessment of the matched variables. Multivariate modelling was conducted using a forward stepwise method to avoid overfitting of parameters. Data are presented as unadjusted (OR) and adjusted ORs (aOR) with accompanying $95 \%$ CI. All tests were two-sided, and a $\mathrm{p}$ value $<0.05$ was considered statistically significant.

The study was reviewed and approved by the hospital's Quality Improvement Committee as having met the 'Australian National Health and Medical Research Council requirements for quality assurance and audit projects'. ${ }^{23}$

\section{RESULTS}

Over the 9 year period, 50 infants and children underwent surgical intervention for SGS: 7/50 (14\%) had congenital SGS and $43 / 50$ (86\%) had SASGS (aged 2 weeks-13 years). Of the 43 with SASGS, 37 were patients who had previously been intubated in the neonatal period, of which, $35 / 37$ (94.6\%) were $<30$-week gestation at birth. Thirty-five neonates were cared for in our NICUs. The other two ex-preterm infants were of 28 -week and 30-week gestation and were born and cared for in another country, hence, further details were not available. Of the two infants $>30$-week gestation, one was a 34 -week neonate with congenital hydrops (dry weight $\sim 2300 \mathrm{~g}$ ) intubated for 16 days with $3.5 \mathrm{~mm}$ ETT; and the other was a 38 -week neonate of $3220 \mathrm{~g}$ intubated for seizures for 3 days with $3.5 \mathrm{~mm}$ ETT. The remaining six patients were PICU graduates (figure 1).

The non-NICU graduates who developed acquired SGS were: a 6-week-old infant with bronchiolitis who was intubated for 5 days; a 3-month-old infant with trisomy 21 who was intubated for 2 days post-cardiac surgery; a 15-month-old with PierreRobin Sequence who had a tracheostomy in the neonatal period which caused SGS; a 9-year-old child with lymphoma who developed SGS secondary to vincristine toxicity; a 9-year-old child with trisomy $9 \mathrm{p}$ who was intubated for 10 days for sepsis and a 13-year-old child with staphylococcal sepsis who was intubated for 10 days and was assumed to have necrotising tracheitis.

Of the seven patients with congenital SGS, two were diagnosed at birth, three patients between 1 and 3 months of age, one patient at 1 year of age and one patient at 12 years of age. The modes of presentation were: stridor in four patients; dyspnoea in one patient and difficulties intubating for an unrelated procedure in two patients. Four patients with congenital SGS had associated syndromes/other anomalies (Di George Syndrome, TAR syndrome/VACTERL association/anorectal anomaly) while it was an isolated finding in the other three patients. All patients underwent a LTR, though two patients had an initial supraglottoplasty, one of which having a temporary tracheostomy prior to LTR. 


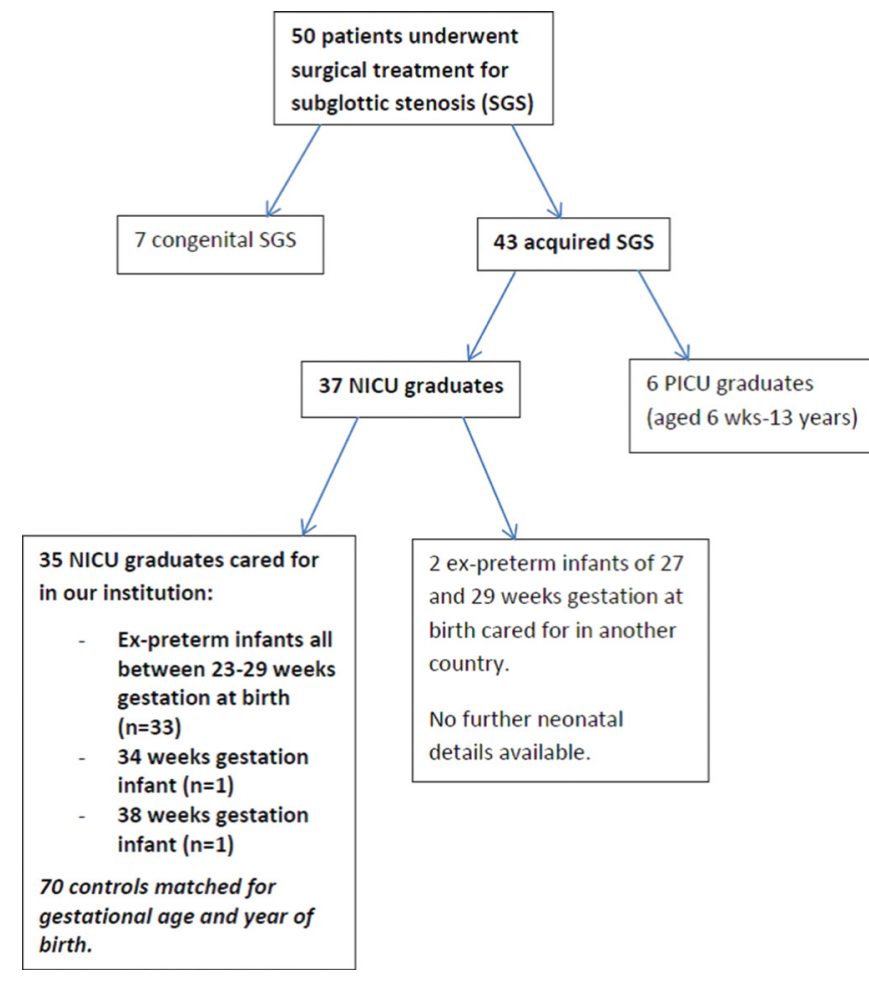

Figure 1 Flow diagram of patient selection (2006-2014). NICU, neonatal intensive care unit; PICU, paediatric intensive care unit; SGS, subglottic stenosis.

Incidence of SGS in neonates in WA (2006-2012)

The incidence of congenital SGS requiring surgical intervention in all live born infants was $4 / 216,748=0.002 \%$, equating to a population incidence of $1.8 / 100,000$ live births.

The incidence of SASGS in surviving previously intubated neonates was $27 / 2913(0.93 \%)$. The overall population incidence was $27 / 216,748=0.012 \%$, equating to a population incidence of 12.5/100,000 live births (table 1). The incidence was higher in preterm infants <28-week gestation $(24 / 623(3.8 \%))$ compared with infants $\geq 28$ weeks $(3 / 2290(0.13 \%) ; p=0.0001)$. The incidence of acquired SGS was almost exclusively confined to infants $<1500 \mathrm{~g}$ at birth (table 2).

Grading of SASGS based on Myer-Cotton classification ${ }^{22}$ Of the 35 patients who underwent surgical intervention for SASGS, on laryngoscopy, 7 patients had grade 2 stenosis, 23 patients had grade 3, and 1 patient had grade 4 on the MyerCotton Classification. ${ }^{22}$ For the remaining four patients, information on the grade was not available.

Age at presentation in NICU graduates

The median chronological age at which symptoms of SASGS appeared was 3.0 months (IQR: 1.9-4.2, R: 0.2 to 78.6). The median chronological age at which LTR was performed was 12.7 months (IQR: 5.9-38.7, R: 3.3 to 151.2 ) and median corrected age (CA) 10.2 months (IQR: 2.0-35.0, R: -0.5 to -147.2 ).

Mode of presentation in NICU graduates

The modes of presentation were: stridor in 20/35 (51.7\%) of which, 9 (45\%) developed stridor during their NICU stay and $11(55 \%)$ post-discharge; failed extubation in the NICU in
Table 1 Incidence of SASGS based on gestational age at birth (2006-2012)

\begin{tabular}{|c|c|c|}
\hline $\begin{array}{l}\text { Gestation at } \\
\text { birth (completed } \\
\text { weeks) }\end{array}$ & $\begin{array}{l}\text { All neonatal } \\
\text { admissions (actual } \\
\text { values, percentage and } \\
95 \% \mathrm{Cl} \text { ) }\end{array}$ & $\begin{array}{l}\text { Neonates intubated and } \\
\text { survived to discharge } \\
\text { from NICU (actual values, } \\
\text { percentage and } 95 \% \mathrm{Cl} \text { ) }\end{array}$ \\
\hline 22 & $0 / 3=0 \%(0 \%$ to $56 \%)$ & $0 / 3=0 \%(0 \%$ to $56 \%)$ \\
\hline 23 & $\begin{array}{l}5 / 88=5.7 \%(2.4 \% \text { to } \\
12.6 \%)\end{array}$ & $5 / 55=9.1 \%(3.94 \%$ to $19.6 \%)$ \\
\hline 24 & $\begin{array}{l}5 / 120=4.2 \%(1.8 \% \text { to } \\
9.4 \%)\end{array}$ & $5 / 99=5.1 \%(2.17 \%$ to $11.3 \%)$ \\
\hline 25 & $\begin{array}{l}5 / 147=3.4 \%(1.5 \% \text { to } \\
7.7 \%)\end{array}$ & $5 / 127=3.9 \%(1.7 \%$ to $8.9 \%)$ \\
\hline 26 & $\begin{array}{l}2 / 197=1.0 \%(0.28 \% \text { to } \\
3.6 \%)\end{array}$ & $2 / 171=1.2 \%(0.32 \%$ to $4.2 \%)$ \\
\hline 27 & $\begin{array}{l}7 / 199=3.5 \%(1.7 \% \text { to } \\
7.1 \%)\end{array}$ & $7 / 168=4.1 \%(2.03 \%$ to $8.35 \%)$ \\
\hline 28 & $\begin{array}{l}1 / 283=0.35 \%(0.06 \% \text { to } \\
1.97 \%)\end{array}$ & $1 / 223=0.45 \%(0.08 \%$ to $2.5 \%)$ \\
\hline 29 & $\begin{array}{l}1 / 310=0.32 \%(0.06 \% \text { to } \\
1.8 \%)\end{array}$ & $1 / 203=0.49 \%(0.09 \%$ to $2.7 \%)$ \\
\hline $30-33$ & $0 / 2536=0 \%(0 \%$ to $0.15 \%)$ & $0 / 676=0 \%(0 \%$ to $0.56 \%)$ \\
\hline $34-36$ & $\begin{array}{l}1 / 4315=0.02(0 \text { to } \\
0.13 \%) \%)\end{array}$ & $1 / 430=0.23 \%(0.04 \%$ to $1.3 \%)$ \\
\hline$>37$ & $0 / 7578=0 \%(0 \%$ to $0.07 \%)$ & $0 / 758=0 \%(0 \%$ to $0.5 \%)$ \\
\hline Overall & $\begin{array}{l}27 / 15,803=0.17 \%(0.12 \% \\
\text { to } 0.25 \%)\end{array}$ & $\begin{array}{l}27 / 2913=0.93 \%(0.64 \% \text { to } \\
1.34 \%)\end{array}$ \\
\hline
\end{tabular}

NICU, neonatal intensive care unit; SASGS, severe acquired subglottic stenosis.

6/35 (17.1\%); symptoms during a viral illness in 5/35 (14.3\%); inability to be weaned off CPAP in 2/35 (5.7\%); and other respiratory symptoms such as dyspnoea/nocturnal symptoms/'wheeze' in $2 / 35(5.7 \%)$.

Type of surgical airway intervention for NICU graduates

Three patients initially underwent a supraglottoplasty at a postmenstrual age (PMA) of 32 weeks, 40 weeks PMA and 2 months CA, respectively, and subsequently all required LTR. Eleven patients underwent an initial tracheostomy at a median PMA of 47 weeks (range 32 weeks PMA-6 months CA). All but three of these patients subsequently underwent LTR at a median CA of 15.5 months (range 5-36 months CA). The median time from tracheostomy to LTR was 15.5

Table 2 Incidence of SASGS based on birth weight (2006-2012)

\begin{tabular}{|c|c|c|}
\hline $\begin{array}{l}\text { Birth } \\
\text { weight }(g)\end{array}$ & $\begin{array}{l}\text { All neonatal } \\
\text { admissions (actual values, } \\
\text { percentage and } 95 \% \mathrm{Cl} \text { ) }\end{array}$ & $\begin{array}{l}\text { Neonates intubated and } \\
\text { survived to discharge } \\
\text { from NICU (actual values, } \\
\text { percentage and } 95 \% \mathrm{CI} \text { ) }\end{array}$ \\
\hline $\begin{array}{l}\text { All } \\
\text { infants }<1500\end{array}$ & $\begin{array}{l}27 / 1988=1.4 \%(0.93 \% \text { to } \\
1.97 \%)\end{array}$ & $27 / 1847=1.5 \%(1 \%$ to $2.1 \%)$ \\
\hline$<500$ & $1 / 43=2.3 \%(0.41 \%$ to $12.1 \%)$ & $1 / 22=4.5 \%(0.81 \%$ to $21.8 \%)$ \\
\hline 500-999 & $19 / 747=2.5 \%(1.63 \%$ to $3.94 \%)$ & $19 / 659=2.9 \%(1.85 \%$ to $4.6 \%)$ \\
\hline 1000-1499 & $6 / 1198=0.5 \%(0.23 \%$ to $1.1 \%)$ & $6 / 1166=0.5 \%(0.23 \%$ to $1.1 \%)$ \\
\hline 1500-1999 & $0 / 2128=0 \%(0 \%$ to $0.18 \%)$ & $0 / 211=0 \%(0 \%$ to $1.79 \%)$ \\
\hline Infants $\geq 2000$ & $\begin{array}{l}1 / 11,687=0.009 \%(0 \% \text { to } \\
0.05 \%)\end{array}$ & $1 / 855=0.12 \%(0.02 \%$ to $0.66 \%)$ \\
\hline Overall & $\begin{array}{l}27 / 15,803=0.17 \%(0.12 \% \text { to } \\
0.25 \%)\end{array}$ & $\begin{array}{l}27 / 2913=0.93 \%(0.64 \% \text { to } \\
1.35 \%)\end{array}$ \\
\hline
\end{tabular}

NICU, neonatal intensive care unit; SASGS, severe acquired subglottic stenosis. 
Table 3 Baseline characteristics of cases and controls

\begin{tabular}{|c|c|c|c|}
\hline & Cases $n=35$ & Controls $n=70$ & pValue \\
\hline $\begin{array}{l}\text { Gestational age } \\
\text { (weeks)* }^{*}\end{array}$ & $\begin{array}{l}25.7(24.0-27.4 ; \\
23.0-38.0)\end{array}$ & $\begin{array}{l}25.4(24.1-27.2 ; \\
23.1-38.9)\end{array}$ & 0.615 \\
\hline Birth weight $(\mathrm{g})^{*}$ & $\begin{array}{l}730(645-1040 \\
410-3220)\end{array}$ & $\begin{array}{l}718 \text { (596-961; 400- } \\
3395)\end{array}$ & 0.274 \\
\hline Male gendert & 23/35 (65.7\%) & $42 / 70(60.0 \%)$ & 0.597 \\
\hline IUGRT & 4/35 (11.4\%) & $11 / 70(15.7 \%)$ & 0.572 \\
\hline $\begin{array}{l}\text { Antenatal } \\
\text { corticosteroidst }\end{array}$ & 29/33 (87.8\%) & $63 / 67(94.0 \%)$ & 0.434 \\
\hline Inbornt & $28 / 34(82.3 \%)$ & $64 / 69(92.7 \%)$ & 0.172 \\
\hline Chorioamnionitis & $3 / 34(8.8 \%)$ & $7 / 69$ (10.1\%) & 1.000 \\
\hline
\end{tabular}

Data represent median (IQR; range) ${ }^{*}$ or $\mathrm{N}(\%) \dagger$ as appropriate unless otherwise specified.

IUGR, intrauterine growth restriction.

months (range 1-35 months). Of the $32 / 35$ who underwent LTR, the procedure occurred at a median CA of 10.5 months (range 0-88 months CA).

\section{Comparison of 35 cases with 70 matched controls}

Baseline characteristics were similar between cases and controls (table 3).

Infants with SASGS were more likely to have had more previous ETTs (median 4 vs $2 ; \mathrm{p}<0.001$ ), an episode of traumatic intubation $(12 / 35(34.3 \%)$ vs $5 / 70(7.1 \%) ; \mathrm{p}=0.003)$, an episode of unplanned extubation (16/35 (45.7\%) vs 14/70 (20.0\%), $\mathrm{p}=0.007$ ]; an oversized ETT (ie, Sherman ratio $>0.1)(26 / 35(74.3 \%)$ vs $30 / 70(42.9 \%) ; p=0.001)$ and ETT for $>7$ days $(28 / 35$ (80\%) vs 40/70 (57.1\%), p=0.00) (table 4). Risk factors evident only in infants with SGS were stridor during neonatal admission 20/35 (57.1\%), acquired CMV 3/35 (8.8\%) and inability to extubate 5/35 (14.3\%).

On multivariate analysis, risk factors for SASGS included: intubation with an ETT with a Sherman ratio >0.1 (aOR: $6.40 ; 95 \%$ CI 1.65 to $24.77 ; \mathrm{p}=0.007$ ); $>5$ previous ETTs (aOR: $3.74 ; 95 \%$ CI 1.15 to $12.19 ; \mathrm{p}=0.029$ ) and traumatic intubation (aOR: 3.37; 95\% CI 1.01 to 11.26 ; $\mathrm{p}=0.048$ ) (table 4). SASGS was diagnosed in only 4/35 (11.4\%) infants with none of these risk factors, $15 / 35$ (42.9\%) with one risk factor and $16 / 35(45.7 \%)$ with two or three risk factors.
Table 5 Risk factors assessed for their influence on SASGS showing unadjusted and adjusted OR and $95 \% \mathrm{CI}$

\begin{tabular}{|c|c|c|}
\hline Risk factor & Unadjusted OR $95 \% \mathrm{Cl}$ & Adjusted OR $95 \% \mathrm{Cl}$ \\
\hline $\begin{array}{l}\text { Episode of intubation } \\
\text { where Sherman ratio }>0.1\end{array}$ & 7.92 (2.25 to 27.92$)$ & 6.40 (1.65 to 24.77$)$ \\
\hline$>5$ previous ETTs & 4.13 (1.46 to 11.71$)$ & $3.74(1.15$ to 12.19$)$ \\
\hline $\begin{array}{l}\text { Episode of traumatic } \\
\text { intubation }\end{array}$ & 4.80 (1.69 to 13.62$)$ & 3.37 (1.01 to 11.26$)$ \\
\hline Duration ETT $>7$ days & 4.65 (1.46 to 14.76$)$ & 1.85 (0.44 to 7.85$)$ \\
\hline $\begin{array}{l}\text { Multiple attempts at } \\
\text { intubation }\end{array}$ & $1.88(0.76$ to 4.62$)$ & 0.94 (0.33 to 2.62 ) \\
\hline Episode of sepsis & 0.57 (0.23 to 1.41$)$ & 0.37 (0.08 to 1.64$)$ \\
\hline
\end{tabular}

ETT, endotracheal tube; SASGS, severe acquired subglottic stenosis.

6/35 (17.1\%) infants had all three risk factors. Other risk factors assessed in the model included ETT for $>7$ days, multiple attempts at intubation, unplanned extubations/100 days ventilated, sepsis and the matched characteristics, all of which were not significant in the adjusted analyses (table 5).

\section{DISCUSSION}

This population based case-control study reports on the association between SASGS and various neonatal risk factors among a modern cohort of NICU graduates from WA. It also reports on the incidence of SASGS across various gestational age and birthweight categories.

Leung and Berkowitz ${ }^{21}$ reported on the population incidence of neonatally acquired SGS in a comparable population in the state of Victoria, Australia. The incidence of 4.95/100,000 live births was lower than our incidence of 12.5/100,000 live births. The possible reason for this disparity was the fact that they included infants only up to 12 months of age at surgery, whereas we included all children up to 14 years of age. The other reason could be the fact that there were no patients born $<24$-week gestation in their cohort.

The incidence of SASGS in our study was $0.93 \%$ out of a total of 2913 children who had required endotracheal intubation and mechanical ventilation in the neonatal period and survived to discharge. Previously reported incidences of SGS in all intubated neonates was $0 \%$ by Walner et $a l^{12}$ and Contencin and Narcy, ${ }^{8}$ but their numbers of ventilated patients were very small (281

Table 4 Potential contributing factors in the development of SASGS by cases and controls

\begin{tabular}{|c|c|c|c|c|c|}
\hline & Cases $\mathrm{n}=35$ & & Controls $\mathrm{n}=70$ & & $\mathrm{p}$ Value \\
\hline Number of previous intubations* & 4 & $(2-9 ; 1-20)$ & 2 & $(1-5 ; 0-8)$ & $<0.001$ \\
\hline$>5$ previous intubations & 15 & $(42.9 \%)$ & 12 & $(17.1 \%)$ & 0.008 \\
\hline Number of days each ETT was in place* & 4.5 & $\begin{array}{l}(3.0-6.3 ; \\
1.0-16.5)\end{array}$ & $\begin{array}{l}4.3 \\
(n=64)\end{array}$ & $\begin{array}{l}(2.0-7.5 ; \\
0.5-26.7)\end{array}$ & 0.359 \\
\hline $\mathrm{ETT}>7$ days $\dagger$ & 28 & $(80 \%)$ & 40 & $(57.1 \%)$ & 0.009 \\
\hline Episode of unplanned extubationt & 16 & $(45.7 \%)$ & 14 & $(20.0 \%)$ & 0.007 \\
\hline$>2$ unplanned extubations $/ 100$ days ventilated $t$ & 15 & $(42.9 \%)$ & 12 & $(17.1 \%)$ & 0.005 \\
\hline Multiple attempts at intubationt & 12 & $(34.3 \%)$ & 15 & $(21.4 \%)$ & 0.170 \\
\hline Episode of traumatic intubationt & 12 & $(34.3 \%)$ & 5 & $(7.1 \%)$ & 0.003 \\
\hline Episode of intubation where Sherman ratio $>0.1 \dagger$ & 26 & (74.3\%) & 30 & $(42.9 \%)$ & 0.001 \\
\hline
\end{tabular}

Data represents median* (IQR; range) or $\mathrm{N}(\%) \dagger$ as appropriate unless otherwise specified.

ETT, endotracheal tube; SASGS, severe acquired subglottic stenosis. 
and 247 , respectively). Other authors reported on a selected population only (eg, patients ventilated for $>48$ hours $^{1013}$ or $>7$ days $\left.{ }^{1416}\right)$ and some reported on a specific groups of neonates. ${ }^{91415}$ Our incidence of 27/1847 (1.5\%) in infants with a birth weight of $<1500 \mathrm{~g}$ is comparable with Suzumura et $a l^{16}$ and Nicklaus $e$ t $a l^{9}$ who reported incidences of $3.1 \%$ and $2.4 \%$ respectively. Gaynor and Danoff ${ }^{15}$ reported an incidence of $0 \%$ in infants $<1500 \mathrm{~g}$, although they only had a denominator of 128 patients.

Acquired SGS has not previously been shown to be associated with gestational age. ${ }^{671617}$ However, previous numbers were small from an era when extremely preterm infants born at 23-week and 24-week gestation infants did not survive. Our figures show that the incidence of SASGS is especially high in surviving extreme premature infants of 23-week and 24-week gestation. This raises the importance of having a high index of suspicion of SGS in such infants, given that $>30 \%$ of our study infants were asymptomatic in the neonatal period. Downing and Kilbride ${ }^{14}$ carried out laryngoscopy on 117 preterm infants who had been intubated for $>7$ days or who had an $\mathrm{O}_{2}$ requirement at 28 days or at 36 weeks CGA and found that $27.3 \%$ had moderate or severe abnormalities and $11.1 \%$ had SGS.

Commonly reported risk factors in the development of acquired SGS are the number of ETTs ${ }^{6791420}$ and length of time intubated. ${ }^{79141824}$ Like previous studies, we found an increased risk of SASGS in infants intubated for $>7$ days, ${ }^{6}$ but not for those intubated $>14^{1624}$ or $>21$ days.

Unplanned extubations (UE) have been suggested as a risk factor for development of SGS. ${ }^{25}$ Da Silva and Stevens showed a link between UE and postextubation stridor, but the patients did not go on to subsequently present with SGS. ${ }^{26}$ Our study found that UE in the neonatal period was associated with acquired SGS on univariate analyses, but not multivariate analysis.

Our study supports findings of previous studies that have shown an association between the size of ETT and subsequent development of SASGS. ${ }^{7814}$ Lima $e^{2} \mathrm{al}^{27}$ showed that the area of the cricoid lumen in extremely preterm infants is smaller than the external diameter of any available ETTs. Sherman and Nelson ${ }^{728}$ proposed the following formula to guide the selection of the appropriate size of that ETT for neonatal intubations: ETT size/ gestationalage $<0.1$ and found this approach to significantly reduce the incidence of SGS in neonates. Based on this formula, infants with gestational age $<30$ weeks would receive $2.5 \mathrm{~mm}$ ETT, those at 31-35 weeks receive $3.0 \mathrm{~mm}$ ETT and $>36$ weeks receive $3.5 \mathrm{~mm}$ ETT. From a cohort of 247 neonates, Contencin and Narcy ${ }^{8}$ showed that intubation with $2.5 \mathrm{~mm}$ ETT for infants $<2.5 \mathrm{~kg}$ and $3.0 \mathrm{~mm}$ ETT for those $2.5-4 \mathrm{~kg}$ resulted in zero incidence of SGS. However, the patients were of higher birth weight and had a shorter duration of intubation than in other studies. The use of such small-sized ETTs could cause problems with ventilation due to large leaks around the ETT. Hence, using the Sherman ratio when selecting the size of ETT and ensuring an appropriate 'leak around the ETT' on intubation has the potential to achieve adequate ventilation, while avoiding the side effects of unduly large ETTs.

A theoretically attractive option to reduce the incidence of SASGS is to use cuffed ETTs for neonatal intubations. ${ }^{29}$ This is due to the fact that the outer diameter of the ETT used is $0.5 \mathrm{~mm}$ smaller for a cuffed ETT than for an uncuffed ETT. This means that there is a smaller ETT through the delicate elliptically shaped ${ }^{27}$ non-distensible cricoid and instead the cuff makes its seal in the trachea where there are U-shaped cartilages and a muscular dorsal wall which allows for some distension. However, as the smallest available cuffed ETT is $3.0 \mathrm{~mm}$
(Microcuff ETT), they are not of use in extremely preterm infants.

In our cohort of infants with SASGS, nearly $44 \%$ did not have stridor in the neonatal period. Holzki et al ${ }^{30}$ cautioned that an airway injury is not always accompanied by postextubation stridor and that it may develop months after extubation as scar tissue forms. Fan $e t a l^{31}$ showed that in 73 consecutively intubated neonates, $38 \%$ with moderate to severe injury on laryngoscopy did not have stridor. On the other hand, all patients with stridor had moderate or major injury. None of our patients without SASGS had stridor during their neonatal stay, suggesting that as demonstrated by Fan et al, ${ }^{31}$ the presence of stridor should alert to the possibility of significant injury.

Suzumura et $a l^{16}$ showed a relationship between infection and development of SGS, however, in our study, there was no correlation with sepsis on multivariate analysis. Of interest, there have been case reports of CMV causing SGS and laryngotracheitis in infants and immunocompromised patients. ${ }^{32-35}$ In our cohort, three patients with SASGS had acquired CMV infection with none in the control group. Though this was an interesting finding, multivariate analysis did not confirm an association.

The main study limitation is that this is a retrospective study, and hence relied on the reporting of procedures and incidents in the medical records, which was suboptimal at times. This is particularly relevant for events such as unplanned extubation and traumatic intubation. It is possible that some of the cases and controls might have moved interstate/overseas and hence were not identified in our ENT database. Although the cohort is large for this type of study, associations do not always equate to cause and effect. Conversely, the associations that did not reach statistical significance cannot be totally dismissed; the lack of apparent significance may simply be due to the fact that the sample size was insufficient to detect a statistically significant difference. Another limitation was that since it was a retrospective study, information on the severity of SGS based on the accepted system of Myer-Cotton grading ${ }^{22}$ was not available from the medical records of all the study infants. A third limitation was that even though we labelled all our cases as having SASGS, there is a possibility that some of them may have had an element of congenital SGS which became symptomatic subsequently. The fourth limitation is that the incidence of SASGS that we have reported may not be generalisable, given that prenatal care of high risk women and postnatal care of preterm infants differ from one country to another and one region in a country to another. The main strengths of this study are the reasonably large size and the inclusion of all SASGS from a state-wide population which included all ventilated neonates in the state. The other strength is the use of multivariate analysis to adjust for potential confounders and the fact that the study population is from the recent decade.

\section{CONCLUSION}

SASGS is a serious consequence of intubation for mechanical ventilation in NICU graduates, especially in extremely preterm infants. Minimising trauma during intubation, avoiding recurrent extubation/intubationsand using appropriate sized ETTs may be potential strategies to prevent this serious complication. Similar studies from other centres will enhance further understanding of the causative factors of this serious condition and also enable benchmarking.

Funding RET was the recipient of a Telethon (Western Australia) Research Fellowship to conduct research involving cuffed ETTs in neonates. This study was part of her Telethon fellowship training. 
Disclaimer The funding source had no role in the design and conduct of the study; collection, management, analysis and interpretation of data; preparation, review or approval of the manuscript; or decision to submit the manuscript for publication.

Competing interests None declared.

Ethics approval Princess Margaret for Hospital for Children Quality Improvement Commitee.

Provenance and peer review Not commissioned; externally peer reviewed.

(C) Article author(s) (or their employer(s) unless otherwise stated in the text of the article) 2018. All rights reserved. No commercial use is permitted unless otherwise expressly granted.

\section{REFERENCES}

1 Holinger PH, Kutnick SL, Schild JA, et al. Subglottic stenosis in infants and children. Ann Otol Rhinol Laryngol 1976;85:591-9.

2 Papsidero MJ, Pashley NR. Acquired stenosis of the upper airway in neonates. An increasing problem. Ann Otol Rhinol Laryngol 1980;89:512-4.

3 Parkin JL, Stevens MH, Jung AL. Acquired and congenital subglottic stenosis in the infant. Ann Otol Rhinol Laryngol 1976;85:573-81.

4 Schreiner MS, Downes JJ, Kettrick RG, et al. Chronic respiratory failure in infants with prolonged ventilator dependency. JAMA 1987;258:3398-404.

5 Strong RM, Passy V. Endotracheal intubation. Complications in neonates. Arch Otolaryngol 1977;103:329-35.

6 Fan LL, Flynn JW, Pathak DR. Risk factors predicting laryngeal injury in intubated neonates. Crit Care Med 1983;11:431-3.

7 Sherman JM, Lowitt S, Stephenson C, et al. Factors influencing acquired subgottic stenosis in infants. J Pediatr 1986;109:322-7.

8 Contencin P, Narcy P. Size of endotracheal tube and neonatal acquired subglottic stenosis. Study Group for Neonatology and Pediatric Emergencies in the Parisian Area. Arch Otolaryngol Head Neck Surg 1993;119:815-9.

9 Nicklaus PJ, Crysdale WS, Conley S, et al. Evaluation of neonatal subglottic stenosis: a 3-year prospective study. Laryngoscope 1990;100:1185-90.

10 Grundfast KM, Camilon FS, Pransky S, et al. Prospective study of subglottic stenosis in intubated neonates. Ann Otol Rhinol Laryngol 1990;99:390-5.

11 Jones R, Bodnar A, Roan Y, et al. Subglottic stenosis in newborn intensive care unit graduates. Am J Dis Child 1981;135:367-8.

12 Walner DL, Loewen MS, Kimura RE. Neonatal subglottic stenosis--incidence and trends. Laryngoscope 2001;111:48-51.

13 Choi SS, Zalzal GH. Changing trends in neonatal subglottic stenosis. Otolaryngol Head Neck Surg 2000;122:61-3.

14 Downing GJ, Kilbride HW. Evaluation of airway complications in high-risk preterm infants: application of flexible fiberoptic airway endoscopy. Pediatrics 1995;95:567-72.

15 Gaynor EB, Danoff SJ. The role of gentle ventilation in prevention of subglottic stenosis in the newborn. Otolaryngol Head Neck Surg 1993;109:701-6.
16 Suzumura H, Nitta A, Tanaka G, et al. Role of infection in the development of acquired subglottic stenosis in neonates with prolonged intubation. Pediatr Int 2000;42:508-13.

17 Albert DM, Mills RP, Fysh J, et al. Endoscopic examination of the neonatal larynx at extubation: a prospective study of variables associated with laryngeal damage. Int $J$ Pediatr Otorhinolaryngol 1990;20:203-12.

18 Dankle SK, Schuller DE, McClead RE. Risk factors for neonatal acquired subglottic stenosis. Ann Otol Rhinol Laryngol 1986;95:626-30.

19 Laing IA, Cowan DL, Ballantine GM, et al. Prevention of subglottic stenosis in neonatal ventilation. Int J Pediatr Otorhinolaryngol 1986;11:61-6.

20 Ratner I, Whitfield J. Acquired subglottic stenosis in the very-low-birth-weight infant. Am J Dis Child 1983;137:40-3.

21 Leung R, Berkowitz RG. Incidence of severe acquired subglottic stenosis in newborns. Int J Pediatr Otorhinolaryngol 2007;71:763-8.

22 Myer CM, O'Connor DM, Cotton RT. Proposed grading system for subglottic stenosis based on endotracheal tube sizes. Ann Otol Rhinol Laryngol 1994;103:319-23.

23 Government A. Ethical Considerations in Quality Assurance and Evaluation Activities. In: Council NHaMR, ed. 2014.

24 Quiney RE, Gould SJ. Subglottic stenosis: a clinicopathological study. Clin Otolaryngol Allied Sci 1985;10:315-27.

25 Brown MS. Prevention of accidental extubation in newborns. Am J Dis Child 1988;142:1240-3.

26 da Silva O, Stevens D. Complications of airway management in very-low-birth-weight infants. Biol Neonate 1999;75:40-5.

27 Lima LF, Nita LM, Campelo VE, et al. Morphometric study on the anatomy of the fetal cricoid cartilage and comparison between its inner diameter and endotracheal tube sizes. Ann Otol Rhinol Laryngol 2008;117:774-80.

28 Sherman JM, Nelson $\mathrm{H}$. Decreased incidence of subglottic stenosis using an "appropriate-sized" endotracheal tube in neonates. Pediatr Pulmonol 1989;6:183-5.

29 Thomas R, Rao S, Minutillo C. Cuffed endotracheal tubes for neonates and young infants: a comprehensive review. Arch Dis Child Fetal Neonatal Ed 2016;101:F16 8-F174.

30 Holzki J, Laschat M, Puder C. Stridor is not a scientifically valid outcome measure for assessing airway injury. Paediatr Anaesth 2009;19 Suppl 1:180-97.

31 Fan LL, Flynn JW, Pathak DR, et al. Predictive value of stridor in detecting laryngeal injury in extubated neonates. Crit Care Med 1982;10:453-5.

32 Kashiwagi Y, Kawashima H, Takekuma K, et al. [Cytomegalovirus (CMV) infection in infants may result intractable stridor]. Kansenshogaku Zasshi 2000;74:675-9.

33 Marelli RA, Biddinger PW, Gluckman JL. Cytomegalovirus infection of the larynx in the acquired immunodeficiency syndrome. Otolaryngol Head Neck Surg 1992; 106:296-301.

34 Reina J, Ferrès F. [Acute laryngotracheitis associated with cytomegalovirus infection] Enferm Infecc Microbiol Clin 2012;30:654-5.

35 Herzig ME, Buttery J, Berkowitz RG, et al. Cytomegalovirus-associated infantile subglottic stenosis responsive to ganciclovir therapy. Int J Pediatr Otorhinolaryngol Extra 2006:1:65-7. 